\title{
Alterações Cardiovasculares na Anemia Falciforme
}

\author{
Wolney de Andrade Martins, Evandro Tinoco Mesquita, Delma Maria da Cunha, Anelise Hagen \\ Ferrari, Luiz A ugusto de Freitas Pinheiro, Luiz José Martins Romêo Fo, Raul Carlos Pareto Jr
}

Niterói, RJ

A anemia falciforme (AF) é uma hemoglobinopatia hereditária atribuída a uma lesão molecular específica, que é a troca do ácido glutâmico por valina no $6^{\circ}$ resíduo da cadeia beta da hemoglobina ${ }^{1}$. Desta troca resulta a polimerização da hemoglobina em longas fibras formando um gel, o que torna a hemácia rígida e em forma de foice, diminuindo então sua flexibilidade e dificultando, conseqüentemente, sua passagem através da microcirculação ${ }^{2}$.

Estudos de biologia molecular identificaram a origem africana deste polimorfismo genético. Há diversos halótipos nas diferentes regiões da África. Os processos migratórios e de colonização levaram a exportação do gene para os povos mediterrâneos e americanos. Na população brasileira, predomina o halótipo CAR beta s como resultado da importação de Angola e do Congo. Com a intensa miscigenação racial, no Brasil, o paciente com AF pode variar do fenótipo de olhos verdes e cabelos loiros ao negro. Na região metropolitana do Rio de Janeiro, encontram-se entre 12 a 14,4\% de falcêmicos brancos ${ }^{3,4}$.

A AF deve ser considerada problema de saúde pública no Brasil, especialmente nas regiões norte e nordeste ${ }^{5}: 1^{\circ}$, por se tratar da doença hereditária de maior prevalência ${ }^{6}$. A hemoglobina $\mathrm{S}(\mathrm{HbS})$ chega a freqüência de 7,6\% da população do nordeste do Brasil, composta de $82 \%$ de negros e mulatos ${ }^{7}$. A forma homozigota manifesta-se entre 0,1 a $0,3 \%$ da população; $2^{\circ}$, pelo diagnóstico tardio, feito geralmente na adolescência, quando são evidentes as lesões em diversos órgãos, como coração, baço e rins. Por interferir na vida escolar de $28,7 \%$, e na vida profissional de $62,5 \%$ dos doentes, acarretando dependência financeira aos responsáveis ou ao Estado; $3^{\circ}$, pela alta morbimortalidade, levando, no Brasil, a uma vida média de $16,4 \pm 12,1 \operatorname{anos}^{8}$. Apresenta uma expectativa de mortalidade 17 vezes maior que a população normal ${ }^{9}$.

Certamente não foi por acaso que a primeira descrição da AF tenha sido feita por um cardiologista. James Herrick relatou, em 1910, o caso de um homem negro, de 20 anos, com dispnéia, palpitações, cardiomegalia, sopro sistólico e pulsos cheios, cujo exame de sangue periférico mostrou

Universidade Federal Fluminense - Niterói

Correspondência: Wolney de Andrade Martins - Coordenação do Mestrado em Cardiologia - Av. Marquês do Paraná, 303 - $2^{\circ}$ - 24033-900 - Niterói, RJ

Recebido para publicação em 2/2/98

Aceito em 18/4/98 hemácias em forma de foice ${ }^{10}$. Nestes 88 anos, muitos aspectos foram esclarecidos com a evolução da metodologia de investigação diagnóstica, todavia restam questões conflitantes. Há poucos estudos prospectivos, em adultos, com metodologia criteriosa, quanto ao diagnóstico eletroforético, padronização de nomenclatura ${ }^{11} \mathrm{e}$ a exclusão de outras causas para cardiopatias. No Brasil, na Universidade Federal Fluminense, têm-se realizado avaliações anatomoclínica, radiológica, fonomecanocardiográfica, ecocardiográfica e dopplerfluxométrica sobre o comprometimento cardiovascular da doença ${ }^{12-20}$. Este trabalho tem por objetivo revisar as alterações cardiovasculares comuns às anemias crônicas e, especialmente, as peculiaridades da AF mais freqüentes e graves ${ }^{21-23}$.

\section{Biologia molecular e fisiopatologia}

As manifestações clínicas da AF podem ser atribuídas às alterações da reologia sangüínea, ou seja, alterações físicas no fluxo sangüíneo ao nível da microcirculação devido, principalmente, à rigidez das hemácias ${ }^{24,25}$. O processo de afoiçamento pode culminar em obstrução, isquemia e dano orgânico irreversível ${ }^{26}$. Esta dificuldade em se deformar é devida à polimerização da $\mathrm{HbS}$ em longas fibras, formando um gel. Vários fatores concorrem para isto. Classicamente, atribui-se a baixa saturação de oxigênio como fator principal. Mais recentemente, tem-se demonstrado que três outros fatores são importantes para a polimerização: a concentração de $\mathrm{HbS}$ e sua composição, o estado de hidratação celular e as alterações na membrana celular do eritrócito ${ }^{2,27-31}$.

A cinética da polimerização, também, é fator determinante. Se o tempo gasto para o processo de gelificação for menor que o tempo necessário para as hemácias transitarem pela microcirculação, provavelmente haverá obstrução. Caso contrário, o fenômeno vasoclusivo será evitado ${ }^{29,30}$.

As lesões na membrana celular do eritrócito e o rearranjo dos polímeros em seu interior, explicariam por que muitas células se mantêm morfologicamente alteradas mesmo após a reoxigenação ${ }^{31}$.

Achados de proliferação da íntima dos grandes vasos, displasia fibromuscular focal em pequenas artérias coronárias, assim como o aumento da atividade dos neutrófilos e do sistema complemento têm sugerido a presença de fatores celulares e humorais ${ }^{26,32,33}$. Portanto, acredita-se que a patogênese da AF seja multifatorial. 


\section{Alterações morfológicas na anemia falciforme}

A cardiomegalia global é notada ao exame físico em 68 a $80 \%$ nas diferentes séries ${ }^{17,18,34,35}$. O estudo radiológico confirma este achado do exame físico em 71 a $84 \%$, sendo que o índice cardiotorácico varia entre 0,54 a 0,58 17,18,36,37.

Os primeiros estudos ao ecocardiograma unidimensional já mostravam que a alteração cavitária mais prevalente era o aumento do átrio esquerdo (AE). O aumento do diâmetro diastólico do ventrículo esquerdo (VE) também é fato indiscutível ${ }^{18,37-44}$. O índice de massa ventricular esquerdo calculado a partir da ecodopplercardiografia (EDC) mostra aumento significativo quando comparados por sexo. Encontra-se nos falcêmicos, portanto, uma hipertrofia excêntrica do $\mathrm{VE}^{14,42,44-46}$.

Todas as alterações são de caráter progressivo, sendo mais exuberantes nos grupos etários mais idosos $3,39,40,44,45,47$. São também, mais freqüentes nos falcêmicos do que naqueles com anemias carenciais ${ }^{48}$. Os achados anatomopatológicos confirmam os dados de imagem. Observam-se dilatação do VE em 44 a 100\% e aumento da massa em 80 a $100 \%^{14,21,45,49,50}$.

O aumento do diâmetro diastólico do ventrículo direito (VD) em valores absolutos é controverso na literatura. Varia entre 15 a $20 \%$ dos pacientes no estudo ecocardiográfico ${ }^{47,51}$. Acredita-se que a dilatação do VD seja mais tardia e menos intensa que a das cavidades esquerdas ${ }^{37,52}$. No nosso grupo de estudos, observou-se aumento do VD relacionado à superfície corporal em $28 \%$ dos casos contra $80 \%$ de aumento do índice de $\mathrm{VE}^{18}$.

\section{Lesões oro-valvares}

A presença de sopro sistólico é o sinal mais freqüente no exame cardiovascular do falcêmico ${ }^{17,34,36,51}$, chegando a $100 \%$ dos pacientes examinados em nossa série ${ }^{18}$ e na de Klinefelter ${ }^{21}$. Entretanto, lesões oro-valvares raramente são encontradas à EDC ou à necropsia. Atribui-se então, o achado ao hiperfluxo ${ }^{46}$. A doença reumática é um diagnóstico diferencial sindrômico da AF, porém se desconhece qualquer correlação. A freqüência de prolapso valvar mitral em falcêmicos é baixa na maioria dos trabalhos ${ }^{17,18,51,53}$, sendo até menor que a esperada para a população geral ${ }^{54}$.

\section{Alterações microscópicas}

Os estudos microscópicos do coração relatam a presença de vacuolização e fragmentação de fibras miocárdicas, edema interfibrilar, degeneração eosinofílica, infiltrado intersticial linfocitário, fibrose interfibrilar, necrose focal, trombos de hemácias afoiçadas e espessamento parietal em arteríolas ${ }^{12-14,34,49,55}$.

Barreto Netto e col denominaram de "lesões infartóides" no miocárdio do falcêmico ao conjunto de hemácias afoiçadas no interior de vasos, áreas focais de fibras miocárdicas isquemiadas, e a redução da luz dos vasos por lesões parietais necróticas com protusão concêntrica, na ausência de lesões ateroscleróticas ${ }^{12-14}$. Como as lesões citadas também foram encontradas em indivíduos não anêmi$\cos$ como os portadores de traço falcêmico ${ }^{12,13}$, não se pode atribuir, exclusivamente, à anemia como fator causal desta agressão ao miocárdio.

Contrastando com as síndromes talassêmicas, a hemossiderose cardíaca é rara na $\mathrm{AF}^{50}$. Corroborando com isto, os parâmetros de função sistólica não diferem entre falcêmicos transfundidos ou não ${ }^{41}$.

\section{Alterações funcionais na anemia falciforme}

Quadro hemodinâmico - A anemia crônica apresentase, fisiopatologicamente, no aparelho cardiovascular como uma síndrome de alto débito. É a doença que mais freqüentemente aumenta o débito cardíaco (DC) em repouso. Este aumento do DC, geralmente, ocorre nas anemias crônicas quando a $\mathrm{HbS}$ é $\leq 7 \mathrm{~g} / \mathrm{dL}$. Na AF ocorre mesmo com níveis de hemoglobina entre 9 e $10 \mathrm{~g} / \mathrm{dL}$. Isto se dá às custas do incremento do volume sistólico, já que, raramente, a taquicardia é encontrada ${ }^{22,23}$.

A pressão arterial (PA) sistólica encontra-se normal, enquanto que a diastólica está diminuída, resultando assim em menor PA média ${ }^{18,22,23}$. Coerentemente, a resistência vascular periférica total e o estresse parietal telessistólico estimados encontram-se significativamente diminuídos, decrescendo proporcionalmente à gravidade da anemia ${ }^{18,37,53}$.

Consideram-se como principais mecanismos de elevação do DC aqueles que diminuem a pós-carga como a vasodilatação periférica e a diminuição da viscosidade sangüínea. A hipóxia leva à acidose lática, à liberação de bradicinina e adenosina e, conseqüentemente, à vasodilatação. Especificamente na AF, a viscosidade sangüínea encontra-se normal ou até mesmo aumentada ${ }^{24,25}$. A précarga está aumentada pelo incremento no volume plasmático total ${ }^{23,40,53}$. O aumento na produção de 2,3 difosfoglicerato desvia a curva de dissociação da hemoglobina para a direita, levando ao aumento da extração tecidual de oxigênio com papel especial na $\mathrm{AF}^{56}$.

Disfunção sistólica do ventrículo esquerdo - É grande dúvida do hematologista e cardiologista clínicos: atribuir as freqüentes queixas de dispnéia e cansaço à anemia ou à insuficiência cardíaca (IC). O diagnóstico de IC em quaisquer das síndromes de alto débito é difícil. Deve-se lembrar que, conceitualmente, o diagnóstico de IC deveria ser feito a partir da análise do metabolismo do oxigênio ou por parâmetros que avaliassem a contratilidade miocárdica e não o desempenho do coração como bomba ${ }^{53}$.

Evidências contrárias à disfunção sistólica do $\mathrm{VE}$ As evidências contrárias foram baseadas, principalmente, nos achados dos índices de fase de ejeção, tais como fração de ejeção, percentual de encurtamento sistólico e índice cardíaco, normais ou aumentados. Concluía-se, então, pela inexistência de disfunção ${ }^{37,38,40,44,47,57-59}$. Porém, Denenberg e col ${ }^{53}$ chamaram a atenção, pela primeira vez, que estes 
parâmetros convencionais, por sofrerem grande influência das alterações da pré e da pós-carga, não serviriam para avaliar a função sistólica em falcêmicos. Argumentaram que os falcêmicos, pelo aumento da pré-carga e diminuição da pós-carga, através do mecanismo de Frank-Starling, apresentariam estes índices normais ou até mesmo aumentados, ocultando a função intrínseca do músculo cardíaco.

Os intervalos sistólicos do VE medidos à fonomecanocardiografia encontram-se normais ${ }^{17,38,60}$. Entretanto, o mesmo não ocorreu nas anemias graves com níveis de hemoglobina $<7 \mathrm{~g} / \mathrm{dL}^{61}$. É sabido que as alterações de carga presentes na anemia crônica podem comprometer estes índices levando a uma pseudo-normalização ${ }^{40}$.

Evidências favoráveis à disfunção sistólica do ventrículo esquerdo - 1) Os falcêmicos encontram-se, em sua maioria, nas classes funcionais II e III da New York Heart Association quanto à tolerância ao esforço ${ }^{18,36,53,57}$; 2) a resposta ao exercício e a capacidade laborativa observadas à ergometria acoplada a cintilografia acham-se diminuídas. A freqüência cardíaca (FC) máxima obtida à ergometria é anormalmente baixa, mesmo em crianças ${ }^{62}$. A elevação da PA e a variação do DC são significativamente menores que a esperada na análise do exercício acoplado ao estudo cintilográfico ${ }^{39,40,63-65} ; 3$ ) a grande freqüência de alterações eletrocardiográficas, entre 35 a $82 \%$ nas séries. As alterações mais comuns são a sobrecarga atrial esquerda e as alterações inespecíficas e difusas da repolarização ventricular $^{14,17,18,23,35,36,46,52,66 ; 4)}$ parâmetros independentes das alterações de carga, como a relação estresse parietal/índice de volume tele-sistólicos mostram, inequivocamente, déficit de contratilidade miocárdica ${ }^{18-20,37,48,53}$. A disfunção sistólica correlaciona-se diretamente com o grau de dilatação cavitária do AE e VE. Esta correlação não ocorre com os índices de fase de ejeção ${ }^{18-20}$; 5) parâmetros indiretos de aferição da função sistólica, como o índice de volume telesistólico do VE e a distância E-septo mitral, encontram-se aumentados em falcêmicos ${ }^{18-20} ; 6$ ) a forma congestiva de insuficiência cardíaca (ICC) manifesta-se entre 5,4 a 7,0\% dos pacientes ${ }^{35,36}$. A ICC é a causa mortis em $8 \%$ dos falcêmicos na região metropolitana do Rio de Janeiro ${ }^{3}$; 7) a presença de isquemia que, sabidamente leva à disfunção miocárdica.

Disfunção diastólica do ventrículo esquerdo - A grande dificuldade na análise da função diastólica em portadores de AF reside no aumento da pré-carga que, seguramente, subestima a disfunção existente nesses doentes ${ }^{67,68}$. Apesar de poucos, os estudos da função diastólica são coerentes em mostrar, através de parâmetros variados, a diminuição de relaxamento ou padrão restritivo na maioria dos doentes ${ }^{18,40,42}$. Falcêmicos com disfunção diastólica têm pior desempenho no teste ergométrico do que aqueles sem alterações. As alterações diastólicas, provavelmente secundárias ao processo isquêmico, pioram proporcionalmente à intensidade do esforço ${ }^{40}$.
Isquemia miocárdica - A presença de angina de peito em falcêmicos é incomum ${ }^{36}$. Apesar dos infartos esplênicos, renais, pulmonares, ósseos, cutâneos e hepáticos serem comuns, o infarto do miocárdio macroscópico é pouco freqüente à necropsia ${ }^{17,45,69}$. Os estudos eletrocardiográficos e ecocardiográficos de séries, também, não encontram maior prevalência de infarto do miocárdio (IM) do que a esperada para a população normal ${ }^{18,35,45,70,71}$. Este aparente contra-senso pode ser explicado pela peculiaridade da alta adaptabilidade da circulação coronária. A anemia crônica e grave acentua a formação de circulação colateral intercoronária ${ }^{46}$. O diâmetro médio coronário é muito maior em falcêmicos ${ }^{45}$. Isto dificulta a possibilidade de infarto transmural no miocárdio, tornando-o mais freqüente em circulações terminais, como a renal. Por outro lado, no traço falcêmico, como não há anemia e seus efeitos adaptativos, parece-nos justificável a possibilidade de uma maior freqüência de IM de origem tromboembólica.

As evidências apontam para o processo isquêmico como fator patogênico da lesão miocárdica na AF. Porém, o processo não é segmentar, como se acreditava, e sim difuso e progressivo. Há muito tem-se advogado que as freqüentes alterações da repolarização ventricular encontradas em eletrocardiogramas de falcêmicos fossem devidas à hipóxia secundária à anemia. Posteriormente, explicou-se a presença da isquemia pelo alentecimento do fluxo sangüíneo na microcirculação devido às alterações morfológicas das hemácias. Na UFF, no início da década de 80 , relatava-se o estreitamento luminal das pequenas artérias coronárias ${ }^{12,14}$. Recentemente, tem-se defendido a hipótese de que o estreitamento luminal, pela displasia fibromuscular focal da parede das artérias tenha papel no processo obstrutivo e isquêmico. $\mathrm{O}$ mesmo achado nas artérias que nutrem o sistema de condução explicaria os inúmeros relatos de morte súbita atribuídos à doença falciforme ${ }^{33}$.

Critérios eletrocardiográficos para isquemia esforçoinduzida são obtidos em 15 a $19 \%$ das crianças ${ }^{62,72}$. Pacientes com sinais eletrocardiográficos de isquemia em repouso apresentam freqüência cardíaca, variação da PA, fração de ejeção, DC e capacidade de trabalho reduzidos, quando submetidos ao exercício ${ }^{39,62}$.

\section{Hipertensão pulmonar e cor-pulmonale}

O diagnóstico diferencial entre embolia, trombose e infecção pulmonares em falcêmicos é considerado difícil ${ }^{73,74}$. A presença de hipertensão arterial pulmonar (HAP) e conseqüente cor-pulmonale é controversa na literatura e tem pouco embasamento científico em estudos de séries ${ }^{22,23,48,74}$. Ao exame físico, observam-se sinais sugestivos de HAP em $18 \%$ dos pacientes ${ }^{48}$. À telerradiografia do tórax, em $20 \%{ }^{17}$. À EDC, são encontrados resultados conflitantes entre $20 \mathrm{a}$ $66 \%$ dos falcêmicos ${ }^{18,51,75}$. Argumenta-se que o alto débito para a circulação pulmonar e a intensa vasodilatação interfiram nas inferências da PA pulmonar ${ }^{48}$, tornando a EDC pouco sensível para o diagnóstico de HAP em falcêmicos. Collins e $\mathrm{col}^{74}$ defendem que, frente a suspeita de HAP e 
cor-pulmonale, o diagnóstico deva ser feito precocemente pelo cateterismo, uma vez que a manifestação por exames não invasivos só se dá tardiamente. Os estudos hemodinâmicos em séries mostram PA pulmonar normal em repouso $^{76,77}$, porém, apresentando níveis anormais ao exercício ${ }^{78}$.

\section{Doença cerebrovascular}

O acidente vascular encefálico (AVE) ocorre entre 7 a $17 \%$ das crianças com $\mathrm{AF}^{79-81}$. Estudo multicêntrico norteamericano concluiu que a manutenção de $\mathrm{HbS}<30 \%$ com terapia transfusional reduz a taxa de novos infartos cerebrais, mas não é eficaz na prevenção de eventos neurológicos transitórios ${ }^{81}$. A manutenção de taxas mais baixas de $\mathrm{HbS}$ reduz o hiperfluxo cerebral ${ }^{82}$. Entretanto, deve-se ponderar a relação entre risco e benefício da terapia transfusional, especialmente quanto à transmissão de doenças infecciosas. Outras complicações neurológicas como embolia gordurosa e trombose de seios cavernosos também são relatadas em falcêmicos. Há estudos que associam o traço falcêmico com maior prevalência de AVEem crianças ${ }^{83}$.

\section{Gestação}

A gestação leva a alterações semelhantes àquelas da $\mathrm{AF}$, como o aumento do volume plasmático e o alto débito, constituindo assim um agravo adicional à falcêmica. As gestantes falcêmicas, no $3^{\circ}$ trimestre, apresentam volume de ejeção e DC muito maiores que as gestantes controles. É relatado uma mortalidade perinatal entre 10 a $14 \%{ }^{84}$.

\section{Álcool}

Desde a década de 60, tem-se observado que a ingestão de álcool pelo heterozigoto está associada ao aparecimento de sintomas semelhantes aos da AF. Observam-se precipitação e/ou agravamento do afoiçamento das hemácias atribuídos a ação direta do álcool, de seu metabólito acetaldeído ou à acidose secundária à intoxicação alcoólica. Acredita-se que o álcool seja um agente desencadeador de fenômenos tromboembólicos em portadores de traço falcêmico ${ }^{12,13,71,85-87}$. Este fato toma vulto ao considerarmos a alta coexistência de alcoolismo e traço falcêmico em nosso meio.

\section{Terapêutica cardiovascular}

Uma vez diagnosticada a disfunção sistólica do VE, surge conseqüentemente a dúvida quanto à abordagem terapêutica. Há escassez de trabalhos que abordem especificamente a terapêutica cardiovascular. $\mathrm{O}$ uso de diuréticos em pacientes onde a hipohidratação deva ser evitada por poder precipitar as crises hemolíticas, parece desacon- selhável. É relatado que o uso de nifedipina leva a melhora nos fenômenos vasoclusivos ao fundo de olho e também nas alterações hematológicas ${ }^{88}$. Parece lógico que um vasodilatador arteriolar possa diminuir o processo isquêmico através da melhora no fluxo ao nível da microcirculação. No entanto, não há uma avaliação específica da ação dessa droga sobre o aparelho cardiovascular neste grupo de doentes. A partir de observação clínica, Blándon e $\mathrm{col}^{52}$ referem-se ao resultado benéfico obtido com baixas doses de inibidores de enzima conversora de angiotensina, digitálico e diurético, especialmente quando associados a antioxidantes (alfatocoferol e ubiquinonas).

\section{Considerações finais}

As discordâncias na literatura entre os resultados devem-se a fatores de duas naturezas: $1^{\circ}$, à escassez de trabalhos atualizados específicos do tema. $2^{\circ}$, a falta de padronização e rigor metodológico nos poucos estudos existentes. Por isso, alerta-se que ao revisar a literatura deve-se considerar criticamente os seguintes fatores de erro: 1) o agrupamento de diferentes hemoglobinopatias com curso clínico e lesões cardiovasculares distintas; 2) o diagnóstico de AF em bases estritamente clínicas, e não eletroforética; 3) o uso de valores absolutos nas variáveis ecocardiográficas, quando é notório a menor superfície corporal dos falcêmicos, influenciando nos resultados de diâmetros cavitários e espessuras musculares; 4) o agrupamento de crianças e adultos, sabendo-se que a doença é progressiva com a idade; 5) o agrupamento de pacientes ambulatoriais com outros sob crises hemolíticas e transfundidos recentes; 6) a inclusão de pacientes com lesões secundárias da AF, como a insuficiência renal, que influenciariam o aparelho cardiovascular.

Apesar das limitações anteriormente descritas, podese concluir, baseado em evidências científicas, que a AF leva a uma hipertrofia excêntrica do VE, ao aumento do átrio e VE e do VD. Leva a uma síndrome de alto débito às custas de uma intensa vasodilatação periférica e do aumento do volume de ejeção. Seguramente, leva a um estado de agressão lenta, contínua e progressiva ao miocárdio, através de um processo isquêmico difuso, que culmina em disfunção da contratilidade miocárdica.

É imperioso que se prossiga com os estudos sobre o comprometimento cardiovascular de todas as doenças falciformes, tão importantes sob o ponto de vista epidemiológico em nosso país.

\section{Agradecimentos}

Aos profs Charles Mady, Francisco Manes Albanesi $\mathrm{F}^{\mathbf{o}}$, Gesmar Volga Haddad Herdy e Marco Antônio Rodrigues Torres pelas sugestões dadas. 


\section{Referências}

1. Embury SH - Sickle cell anemia and associated hemoglobinopathies. In: Bennett, JC, Plum, F, eds - Cecil Textbook of Medicine, $20^{\text {th }}$ ed. Philadelphia: WB Saunders, 1996: 882.

2. Briehl RW - Nucleation, fiber growth and melting, and domain formation and structure in sickle cell hemoglobin gels. J Mol Biol 1995; 245: 710-23.

3. Hutz MH - História natural da anemia falciforme em pacientes da região metropolitana do Rio de Janeiro (Tese Doutorado em Ciências). Porto Alegre, UFRGS, 1981: 275 p.

4. Powards DR - Sickle cell disease in nonblack persons. JAMA 1994; 271: 1885.

5. Naoum PC - Distribuição geográfica das hemoglobinopatias. In: Naoum PC Hemoglobinopatias e Talassemias. São Paulo: Sarvier, 1997: 137-43.

6. Ramalho AS - As hemoglobinopatias hereditárias: um problema de saúde pública no Brasil. Ribeirão Preto: Sociedade Brasileira Genética, 1986.

7. Zago MA, Costa FF - Hereditary hemoglobin disorders in Brazil. Trans R Soc Trop Med Hyg 1995; 79: 385-8.

8. Silva RBP, Ramalho AS, Cassorla RMS - A anemia falciforme como problema de saúde pública no Brasil. Rev Saúde Pública 1993; 27: 54-8.

9. Serjeant GR - Five-year follow-up of Jamaican adults with sickle cell anemia. $\mathrm{Br}$ Med J 1975; 3: 20-1.

10. Herrick JB - Peculiar elongated and sickle-shaped red blood corpuscules in a case of severe anemia. Arch Intern Med 1910; 6: 517-21.

11. Konotey-Ahulu FID - The sickle cell diseases: clinical manifestations inclunding the "sickle crisis". Arch Intern Med 1974; 133: 611-19.

12. Pareto Jr RC, Porto MAT, Couto AA et al - Miocardiopatias congestivas dificuldades diagnósticas - aspectos clínicos e anatomopatológicos. Arq Bras Med 1982; 56: 241-7.

13. Assaf M, Hahn MD, Torres M, Barreto Neto M, Victer H - Sessão clínicopatológica do Hospital Universitário Antonio Pedro - UFF. Arq Bras Med 1983; 57: 81-5.

14. Herdy GVH, Aguas AFF, Chedid TC - Alterações cardíacas na anemia falciforme. Arq Bras Cardiol 1983; 40: 311-15.

15. Herdy GVH, Couto AA, Kurdian B et al - Miocardiopatia na eritrofalcemia: estudo clínico e ecocardiográfico. AC Cardiol 1984; 6: 27-32.

16. Herdy GVH-Alterações cardíacas na eritrofalcemia (Tese para concurso para Professor Titular do Departamento Materno-Infantil), Niterói - UFF, 1985:99 p.

17. Herdy GVH, Pinheiro LAF, Couto AA, Gabetto M - Miocardiopatia e anemia falciforme em crianças. Arq Bras Cardiol 1987; 49: 87-93.

18. Martins WA - Perfil cardiovascular em adolescentes e adultos jovens portadores de anemia falciforme (Tese para obtenção do grau de Mestre em Cardiologia), Niterói - UFF, 1997: 130p.

19. Martins WA, Mesquita ET, Cunha DM, Rômeo LJM, Pinheiro LAF - Disfunção sistólica na anemia falciforme: estudo da contratilidade intrínseca do miocárdio. Rev Bras Eco 1997; (supl especial - maio): TL 70.

20. Martins WA, Mesquita ET, Cunha DM, Rômeo LJM, Pinheiro LAF, Pareto, RC Systolic dysfunction in sickle cell anemia: The stress-volume relation as an independent parameter. In: Anais do First Annual Scientific Meeting of the Heart Failure Society of America. Baltimore: Heart Failure Society of America, 1997: 194.

21. Klinefelter HF - The heart in sickle cell anemia. Am J Med 1942: 203: 34-51.

22. Varat MA, Adolph RJ, Fowler NO-Cardiovascular effects of anemia. Am Heart J 1972; 83: 415-26.

23. Lindsay JJ, Meshel JC, Patterson H- The cardiovascular manifestations of sickle cell anemia. Arch Intern Med 1974; 133: 643-51.

24. Klug PP, Lessin LS, Radice P - Rheological aspects of sickle cell disease. Arch Intern Med 1974; 577-90.

25. Horne MK - Sickle cell anemia as a rheologic disease. Am J Med 1981; 70: 28898.

26. Peters M, Plaat BEC, Cate HT, Wolters HJ, Weening RS, Bradjes DPM-Enhanced thrombin generation in children with sickle cell disease. Thromb Haemostas 1994; 71: 169-72.

27. Clark MR - Mean corpuscular hemoglobin concentration and cell deformability. In: Whitten CF, Bertles JF, eds - Sickle cell disease. New York: New York Academy of Sciences, 1989: 284-94.

28. Lew VL, Bookchin RM-Osmotic effects of protein polymerization: analyses of volume changes in sickle cell anemia red cells following deoxy-hemoglobin $\mathrm{S}$ polymerization. J Membrane Biol 1991; 122: 55-67.

29. Briehl RW, Nikolopoulou P - Kinetics of hemoglobin S polymerization and gelation under shear: shape of the viscosity progress curve and dependence of delay time and reaction rate and temperature. Blood 1993; 81: 2420-8.

30. Briehl RW, Guzman AE - Fragility and structure of hemoglobin S fibers and gels and their consequences for gelation kinetics and rheology. Blood 1994; 83: 573-9.
31. Hiruma H, Noguchi CT, Uyesaka N et al - Sickle cell rheology is determined by polimer fraction - not cell morphology. Am J Hematol 1995; 48: 19-28.

32. Mohamed AO, Hashim MS, Nilsson UR, Venge $P$ - Increased in vivo activation of neutrophils and complement in sickle cell disease. Am J Trop Med Hyg 1993; 49: 799-803.

33. James TN, Riddick L, Massing GK - Sickle cell and sudden death: morphologic abnormalities of the cardiac conduction system. J Lab Clin Med 1994; 124: 50720 .

34. Uzsoy NK - Cardiovascular findings in patients with sickle cell anemia. Am J Cardiol 1964; 13: 320-8.

35. Karayalcin G, Rosner F, Kim KY, Chandra P, Aballi AJ - Sickle cell anemia: clinical manifestations in 100 patients and review of the literature. Am J Med Sci 1975; 269: 51-68.

36. Louis-Gustave A, Louis-Gustave R - Signes cardiovasculaires de la drépanocytose. Arch Mal Coeur 1977; 70: 135-40.

37. Estrade G, Poitrineau O, Bernasconi F, Garnier D, Donatien Y - Fonction ventriculaire gauche et drépanocytose. Arch Mal Coeur 1989; 82: 1975-81.

38. Gerry JL, Baird MG, Fortuin NJ - Evaluation of left ventricular function in patients with sickle cell anemia. Am J Med 1976; 60: 968-72.

39. Covitz W, Eubig C, Balfour IC et al - Exercise-induced cardiac dysfunction in sickle cell anemia: a radionuclidestudy. Am J Cardiol 1983; 51: 570-5.

40. Balfour IC, Covitz W, Davis H, Rao PS, Strong WB, Alpert BS - Cardiac size and function in children with sickle cell anemia. Am Heart J 1984; 108: 345-50.

41. Gaffney JW, Bierman FZ, Donnelly CM, Sutton M, Piomelli S, Gersony WM Cardiac adaptations to transfusion/chelation therapy of homozygote sickle cell anemia. Am J Cardiol 1988; 62: 121-30.

42. Lewis JF, Maron BJ, Castro O, Moosa YA - Left ventricular diastolic filling abnormalities identified by Doppler echocardiography in assymptomatic patients with sickle cell anemia. J Am Coll Cardiol 1991; 17: 1473-8.

43. Kilick Y, Acarturk E, Kumi M - Echocardiographic findings in mild and severe forms of sickle cell anemia. Acta Paediatr Jpn 1993; 35: 243-6.

44. Covitz W, Esperland M, Gallagher D, Hellenbrand W, Leff S, Talner N- The heart in sickle cell anemia: the cooperative study of sickle cell disease. Chest 1995; 108: 1214-19.

45. Gerry JL, Bulkley BH, Hutchins GM - Clinicopathologic analysis of cardiac dysfunction in 52 patients with sickle cell anemia. Am J Cardiol 1978; 42: 211-16.

46. Shulman LN, Braunwald E, Rosenthal DS - Hematological-oncological disorders and heart disease. In: Braunwald E, eds - Heart Disease - A Textbook of Cardiovascular Medicine, $5^{\text {th }}$ ed. Philadelphia: WB Saunders, 1997: 1786-808.

47. Lester LA, Sodt PC, Hutcheon N, Arcilla RA - Cardiac abnormalities in children with sickle cell anemia. Chest 1990; 98: 1169-74.

48. Bertrand E - Drépanocytose et coeur. Arch Mal Coeur 1989; 82: 1881-4.

49. Oliveira E, Gómez-Palatino-Falcemic cardiopathy: report of a case. Am J Cardiol 1963; 11: 686-9.

50. Martin C, Cobb C, Johnson C, Tatter D, Haywood LJ - Cardiovascular pathology in sickle cell disease. Clinical Research 1983; 31: 13A.

51. Simmons BE, Santhanam V, Castaner A, Rao KRP, Sachdev N, Cooper R-Sickle cell disease: two-dimensional echo and Dopplerultrasonographic findings in the hearts of adult patients with sickle cell anemia. Arch Intern Med 1988; 148: 1526-8.

52. Blandón R, Leandro IM, Altafulla M, Fernández RD - Evaluation ecocardiografica de pacientes con anemia falciforme. Rev Med Panamá 1991; 16 $88-97$.

53. Denenberg BS, Criner G, Jones R, Spann JF - Cardiac function in sickle cell anemia. Am J Cardiol 1983; 51: 1674-78.

54. Brown J, Covitz W, Geer M - Mitral valve prolapse in sickle cell anemia. Arch Intern Med 1986; 146: 208.

55. Girardet JP, Beauvais P, Laurent F - Les cardiomegalies drépanocytaires de l'enfant. Arch Fr Pediatr 1983; 40: 525-30.

56. Falk RH, Hood Jr WB - The heart in sickle cell anemia. Arch Intern Med 1982; 142: $1680-4$.

57. Rees AH, Stefadouros MA, Strong WB et al - Left ventricular performance in children with homozygous sickle cell anaemia. Br Heart J 1978; 40: 690-6.

58. Manno BV, Burka ER, Hakki A, Manno CS, Iskandrian AS, Noone AM Biventricular function in sickle-cell anemia: radionuclide angiographic and thallium-201 scintigraphic evaluation. Am J Cardiol 1983; 52: 584-7.

59. Ayuo PO, Abinya NA, Joshi MD, Lore W - Cardiovascular features in adolescents and adults with sickle cell anaemia. East Afr Med J 1993; 70: 270-6.

60. Matsubara LS, Trezza E, Machado PEA - Estudo fonomecanocardiográfico de portadores de hemoglobinopatia S. Arq Bras Cardiol 1981; 36: 185-7.

61. Abdullah AK, Siddiqui MA, Tajuddin M - Systolic time intervals in chronic anemia. Am Heart J 1977; 94: 287-91. 
62. Alpert BS - Hemodinamic and ECG responses to exercise in children with sickle cell anemia. Am J Dis Child 1981; 135: 362-6.

63. Covitz W, Balfour IC, Alpert BS - The heart as target organ in sickle cell anemia. J Cardiovasc Ultrassonography 1986; 5: 177-81.

64. Cullar JFB, Valds RC, Molinos MB - La probable existencia de cardiomiopatia en un grupo de sicklemicos estudiados por ventriculografia nuclear. Rev Cuba Med 1989; 28: 485-90

65. Braden DS, Covitz W, Milner PF - Cardiovascular function during rest and exercise in patients with sickle-cell anemia and coexisting alpha thalassemia-2. Am J Hematol 1996; 52: 96-102.

66. Holloman KL, Johnson CS, Haywood LJ - Electrocardiogram analysis in adult patients with sickle cell disease. J Natl Med Assoc 1987; 79: 809-14.

67. Choong CY, Herrmann HC, Weyman AE - Preload dependence of Doppler-derived indexes of left ventricular diastolic function in humans. J Am Coll Cardiol 1987; 10: 800-808.

68. Stoddard MF, Pearson AC, Kern MJ, Ratcliff J, Mrosek DG, Labovitz AJ-Influence of alteration in preload on the pattern of left ventricular diastolic filling as assessed by Doppler echocardiography in humans. Circulation 1989; 79: 1226-36.

69. Berezowski, K, Mautner, GC, Roberts, WC - Scarring of the left ventricular papillary muscles in sickle-cell disease. Am J Cardiol 1992; 70: 1368-74

70. McCormick WF - Abnormal hemoglobins: incidence in Memphis and western Tenessee, with special reference to autopsy material. Am JClin Path 1960;34:220-4.

71. McCormick WF - Abnormal hemoglobins: the pathology of the sickle cell trait Am J Med Sci 1961;241:329-35.

72. McConnell ME, Daniels SR, Lobel J, James FW, Kaplan S - Hemodynamic response to exercise in patients with sickle cell anemia. Pediatr Cardiol 1989; 10 : $141-4$

73. Bromberg PA - Pulmonary aspects of sickle cell disease. Arch Intern Med 1974 133: 652-7

74. Collins FS, Orringer EP - Pulmonary hypertension and cor pulmonale in the sickle hemoglobinopathies. Am J Med 1982; 73: 814-21.
75. Sutton LL, Castro O, Cross DJ, Spencer JE, Lewis JF - Pulmonary hypertension in sickle cell disease. Am J Cardiol 1994; 74: 626-8.

76. Shubin H, Kaufman R, Shapiro M - Cardiovascular findings in children with sickle cell anemia. Am J Cardiol 1960; 6: 875-85.

77. Mardele $\mathrm{T}-\mathrm{La}$ fonction ventriculaire gauche: étude échocardiographique et hemodinamique. Cardiol Trop 1987; 13: 75-6.

78. Moser KM, Luchsinger PC, Katz S - Pulmonary and cardiac function in sickle cell lung disease: preliminary report. Chest 1960; 37: 637-48.

79. Balkaran B, Char G, Morris JS, Thomas PW, Serjeat GR - Stroke in a cohort of patients with homozigous sickle cell disease. J Pediatr 1992; 120: 360-6.

80. Mercuri E, Faundez JC, Roberts I - Neurological "soft" signs may identify children with sickle cell disease who are at risk for stroke. Eur J Pediatr 1995; 154: 150-6.

81. Pegelow $\mathrm{CH}$, Adams RJ, McKie V - Risk of recurrent stroke in patients with sickle cell disease treated with erytrocite transfusions. J Pediatr 1995; 126: 896899.

82. Hurlet JAM, Prohovnik I, Pavlakis SG, Piomelli S- Effects of totalhemoglobin S concentration on cerebral blood flow during transfusion therapy to prevent stroke in sickle cell disease. Stroke 1994; 25: 1688-92.

83. Partingson MD, Aronyk KE, Byrd SE - Sickle cell trait and stroke in children. Pediatr Neurosurgery 1994; $20: 148-51$

84. Veille JC, Hanson R - Left ventricular systolic and diastolic function in pregnant patients with sickle cell disease. Am J Obstet Gynecol 1994; 170: 107-10.

85. Rubler S, Fleischer RA - Sickle cell states and cardiomyopathy: sudden death due to pulmonary thrombosis and infarction. Am J Cardiol 1967; 19: 867-73.

86. Fleischer RA, Rubler S - Primary cardiomyopathy in nonanemic patients: association with sickle cell trait. Am J Cardiol 1968; 22: 532-7.

87. Rubler S, Fleischer RA, Roth E-Alcohol induced alterations of red cell morphology in carriers of the sickle cell trait. Brit J Haemat 1969; 16: 157-60.

88. Rodgers GP, Roy MS, Noguchi CT, Schechter AN - Use of seletive vasodilatation in treatment of sickle cell disease. Am J Pediatr Oncol 1988; 10: 351-6. 